\title{
HIVIAIDS; ORAL COMPLICATIONS AND CHALLENGES, THE NIGERIAN EXPERIENCE
}

\author{
*M UKPEBOR; **O.B BRAIMOH \\ DEPARTMENT OF *ORAL MEDICINE, **PREVENTIVE DENTISTRY \\ UNIVERSITY OF BENIN TEACHING HOSPITAL, BENIN CITY, NIGERIA
}

\section{ABSTRACT}

So many oral complications of HIVIAIDS abound, these lesions can occur at any stage of the disease and can be used for early recognition of the disease so that prompt treatment can be commenced in order to prevent further complications. A number of work have been done on oral lesions associated with HIV infection in Nigeria.

A review is made of the possible oral complications and challenges of HIVIAIDS in Nigeria, with special emphasis on some specific HIV- related oral lesions which are easily identified, for the purpose of diagnosis, prognosis and to reduce morbidity and mortality in HIVIAIDS.

KEYWORDS: HIVIAIDS, Complications, Challenges, Nigeria.

\section{INTRODUCTION}

It has been estimated that $90 \%$ of people with HIV disease will present with at least one oral manifestation at sometime during the course of their infection ${ }^{1}$. The ability to differentiate one manifestation from another, as well as manage some of the more common conditions is fundamental to the overall health care of this patient population. Dentist as a key player in the primary health care of patients have the ability to positively affect the well being of patients.

There have been a large number of studies published over the years on oral manifestations of HIV. In Nigeria, these oral lesions continue to occupy a place of importance because of its significance in the prevention, diagnosis and management of HIV infection as a whole.

The oral cavity is an important and frequently undervalued source of diagnostic and prognostic information in patients with HIV disease ${ }^{2}$.

Studies of oral conditions associated with HIV infection in adult Nigerians reported prevalence of oral lesions ranging from $20 \%$ in 2001 to $84 \%$ in 2006. Similar studies carried out among HIV infected children reported prevalence of oral lesions to be $87.2 \%^{3-6}$.

A variety of conditions have been described affecting oral tissues in HIV infection ${ }^{7}$. The most common oral lesion is oral candidiasis, with pseudomembranous type the most frequent ${ }^{2,3,8}$. Historically, this was one of the first documented oral features of AIDS and several studies have confirmed its high prevalence ${ }^{9,10}$. Oral lesions can appear at any stage of HIV infection with higher occurrence associated with increasing immunosuppression, and are more frequent in women than in men, and the most common pathogen is Candida albicans ${ }^{8}$.

Recognition of the oral manifestations of HIV disease is of great significance because they may represent the first signs of the disease. They have been shown to be highly predictive markers of severe immune deterioration and disease progression and therefore serve

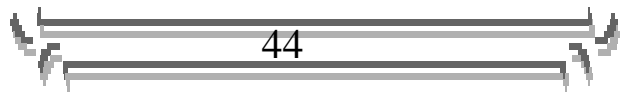


as a clinical correlates of CD4+ counts $^{11,12}$. However, many respond to simple therapeutic measures ${ }^{13}$.

\section{FACTORS PREDISPOSING TO ORAL LESIONS}

A number of factors have been documented to predispose to oral lesions in HIV infected individuals these include

a) CD4 T cell counts $<200$ cells $/ \mathrm{mm}^{3}$

b) High viral load

c) Poor oral hygiene

d) Xerostomia

e) Smoking

f) Low innate immunity

g) Late presentation

h) Malnutrition.

\section{SIGNIFICANCE OF ORAL LESIONS IN} HIVIAIDS

Diagnosis: oral lesions may be the first sign of the disease and therefore serve as a prompt for HIV screening and diagnosis.

Markers: may serve as markers for early immune deterioration and disease progression $^{5}$.

Prognosis: clinical indicators of a poor prognosis e.g. oral thrush, herpes zoster, hairy leukoplakia.

Oral manifestations have been important entry criteria for clinical trials as well as for vaccine studies.

Some of these lesions may compromise the patient's appearance e.g. herpes zoster and facial nerve palsy.

May be one of the earliest lesions of HIV infection and some of them herald rapid deterioration and sometimes, death.

Some of these lesion have a fatal outcome e.g. Kaposi's sarcoma.

Some others are painful, compromising food intake and nutrition
They are indicators of progression to AIDS defining conditions.

Serve as universal component of HIV classification and staging scheme.

ORAL COMPLICATIONS OF HIVIAIDS

Oral lesions associated with HIV infection are classified as stated below:

COMMONLY ASSOCIATED INFECTIONS:

Fungal: Candidiasis

Erythematous

Hyperplastic

Pseudomembranous

Angular cheilitis

Viral:

Herpes simplex

Varicella zoster

Hairy leukoplakia

Bacterial:

HIV-associated gingivitis (LGE:

Linear gingival erythema).

HIV- associated periodontitis (NUP:

Necrotizig ulcerative periodontitis).

Necrotizing gingivitis

Tumours:

Kaposi's sarcoma

Lymphadenopathy

\section{LESS COMMONLY ASSOCIATED}

Atypical ulceration

Salivary gland disease:

Xerostomia due to decreased salivary flow rate.

unilateral/bilateral swelling of major salivary gland especially the parotid glands.

Tumour

Non-Hodgkin lymphoma

Viral:

human papilloma virus (warty-like lesion)

cytomegalovirus

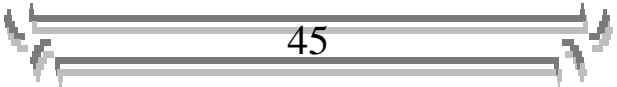


Bacterial:

Mycobacterium tuberculosis

E. coli

Submandibular cellulitis

Sinusitis

Deep mycoses:

Histoplasmosis

Cryptococcus neoformans

Neurological disturbances:

Facial palsy

Trigeminal neuropathy

Miscellaneous:

Delayed wound healing

Thrombocytopenic purpura

Melanotic hyperpigmentation

Recurrent aphthae

Progressive necrotising

ulceration

Osteomyelitis

Drug reactions (ulceration, erythema multiforme, lichenoid reaction).

\section{ORAL CANDIDIASIS}

Candida infections seen in HIVIAIDS patients include Pseudomembranous candidiasis, Erythematous candidiasis, Hyperplastic candidiasis and Angular cheilitis. It is the commonest oral manifestation of HIVIAIDS.

In Nigeria, the prevalence of oral candidiasis range between $36.4 \%$ and $80 \%$ (Onunu and Obuekwe 2002). The most commonly reported Candida infection is Pseudomembranous candidiasis (Thrush) $^{3}$, and has the following features:

It is the most frequently encountered opportunistic infection of the oral cavity. $(>70 \%)$ and appear as white soft creamy patches on any oral mucosa which can easily be wiped off, leaving an erythematous base. But most commonly found in the palate, followed by the tongue, labial mucosa, buccal mucosa, gingival and the floor of the mouth. It indicates declining immunity.

Approximately $50 \%$ of patients with HIV- associated thrush are likely to develop AIDS in 5 years.

Sometimes it may be generalized, and this represents low immunity and must be vigorously treated to prevent systemic dissemination. It is usually associated with angular cheilitis

Erythematous candidiasis usually present on the dorsal surface of the tongue and/or roof of the mouth as a red flat lesion. It is probably the most underdiagnosed oral disease seen in people living with HIV infection. The chief complain is burning sensation associated with eating salty or spicy foods ${ }^{1}$.

Angular Cheilitis: This lesion is more prevalent in $\mathrm{HIV}+$ individuals when compared to HIV- individuals, but does occur in both populations. Angular cheilitis, of itself is not diagnostic of HIV infection. It appears as cracks or fissures radiating from the corners of the mouth which may or may not be accompanied by intraoral "thrush"1,10.

Hyperplastic Candidiasis: This type of candidiasis is unusual in persons with HIV infection. The lesions appear white and hyperplastic. The white areas are due to hyperkeratosis and, unlike the plaques of Pseudomembranous candidiasis, cannot be removed by scraping. These lesions may be confused with hairy leukoplakia. Diagnosis of hyperplastic candidiasis is made from the histologic appearance of hyperkeratosis and the presence of hyphae. Periodic acid-Schiff (PAS) stain is often used to demonstrate hyphae ${ }^{1,2}$.

Most studies carried out in Nigeria, reported Pseudom-embranous candidiasis to be the commonest variant followed by

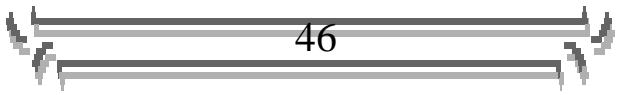


erythematous candidiasis. However, Taiwo et $a l^{8}$ reported Pseudomembranous candidiasis and angular cheilitis as the most common variants and all cases of erythematous candidiasis reported in this study were exclusively seen in the female population ${ }^{8}$. While candidiasis may suggest the possibility of HIV infection, recurring candidiasis is a pointer to HIV infection in Africa.

\section{TREATMENT}

Treatment varies according to the degree of immunosuppression in the patient. For minimally immunocompromised patients, nystatin solution swished and swallowed five times daily is often successful ${ }^{1}$.

In moderate cases of immunosuppression, systemic antifungal agents are used, such as fluconazole (Diflucan), at $200 \mathrm{mg}$ for the first dose, then $100 \mathrm{mg}$ once a day for several days to several weeks, depending on the severity of disease and the response of the patient to treatment. Prophylactic use of antifungal agents is indicated in patients with frequent episodes (e.g., fluconazole in a dosage of $100 \mathrm{mg}$ orally once a week). When patients present with symptoms of dysphagia or odynophagia, the esophagus should also be evaluated to rule out esophageal candidiasis. Azole-resistant oropharyngeal or esophageal candidiasis can be treated with fluconazole in a very high dosage (800 mg per day) or amphotericin $\mathrm{B}^{1,2}$.

It is very important for people who wear partial or complete dentures to treat these appliances when they have candidiasis. This can be done by thoroughly cleaning the denture once a day and soaking it overnight in a 1:1 dilution of a chlorhexidine solution. Patients are also instructed to place 1 $\mathrm{ml}$ of amphotericin Oral Suspension on the acrylic of their denture two to four times per day before inserting the prosthesis $^{1,10}$.

\section{VIRAL MUCOSAL INFECTIONS}

\section{HAIRY LEUKOPLAKIA}

This is probably due to opportunistic Epstein-Barr virus (EBV) infection of the epithelial cells. It may herald HIV disease in vast majority of cases, and also may be present after AIDS is established. It is the second most prevalent oral lesion in the world, however, the reported incidence is lower in Nigeria with a range of $4.4 \%-9.9 \%{ }^{3,14,15}$.

Hairy leukoplakia is highly characteristic of HIV infection especially in male homosexuals. It appears as a soft, corrugated, painless plaques or white patches on lateral borders of tongue and can extend to involve the dorsum of tongue and buccal mucosa. The surface may be so thick as to produce hair-like projections. Fig $1^{16}$.

It is asymptomatic and rarely seen in children. Most often it coexists with oral candidiasis and may be masked by it. It is an indication of advanced immunodeficiency, a more rapid progression to AIDS and a poor prognosis.

It can be diagnosed by demonstration of EBV antigens in epithelial cell nuclei by in-situ hybridisation. Incisional biopsy is also useful in its diagnosis, this show characteristic EBV nuclear inclusions in upper-layer keratinocytes

Hairy leukoplakia rarely requires treatment, it may resolve spontaneously. However can be treated with zidovudine (Retrovir) or high doses of acyclovir (800 mg four times per day)

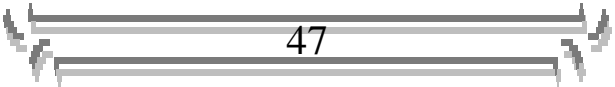




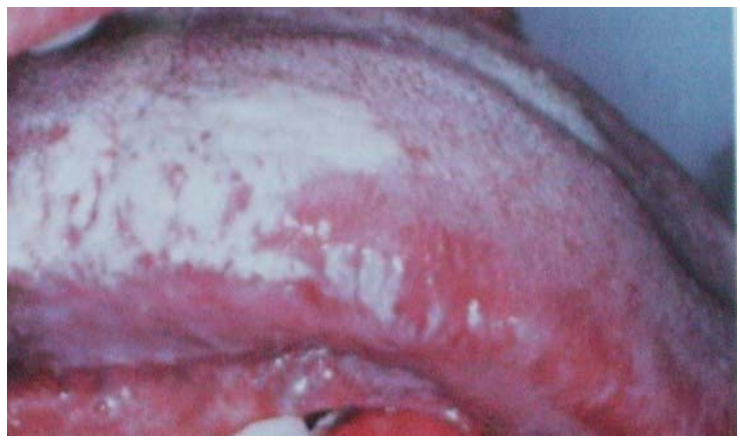

Fig. 1: Hairy Leukoplakia ${ }^{16}$

\section{HERPES SIMPLEX}

It is caused by Herpes simplex virus type 1, common in childhood with a prevalence of $10 \%$ in Nigerian children infected with HIV/AIDS ${ }^{6}$. The 2006 report from Nigeria noted a prevalence of $5.5 \%$ in adults ${ }^{8}$.

It is characterised by vesicles, which rupture to form ulcers which are the most common form of infectious oral ulcers affecting any part of the oral mucosa Fig 2. In immunocompetent individual it affects only the gingiva and hard palate

Usually a prolonged or severe infections and herpetic ulceration persisting for more than a month is an AIDS defining illness

Herpes labialis represents a recurrent infection which presents with multiple grouped, fragile vesicles or ulcers on the vermillion border of the lip or adjacent skin. The vesicles may coalesce to form larger vesicles which heal slowly. In HIVIAIDS lesion may occur in any oral sites and are more severe and prolonged.

Treatment of herpetic lesions in HIVpositive persons consists of acyclovir (or a similar antiviral agent) in a dosage of $200 \mathrm{mg}$ five times a day. This treatment is effective only if started early in the course of the lesion. Mild to moderate oral herpetic lesions should be treated with oral acyclovir. In severely immunocompromised patients with frequent recurrence of oral herpetic lesions, prophylaxis with acyclovir is indicated. Foscarnet can be used in cases of acyclovir-resistant oral herpetic lesions.

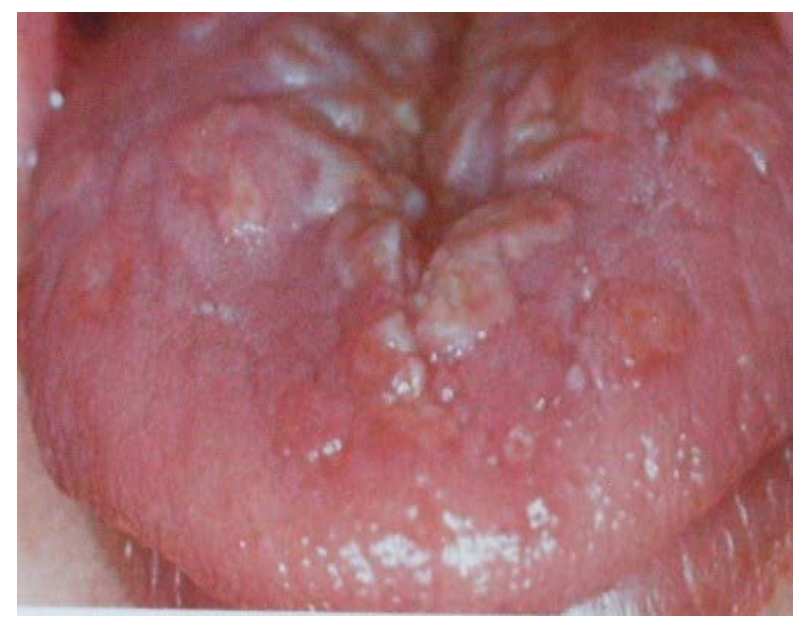

Fig. 2: Herpetic Ulceration in HIV patient $^{16}$

\section{HERPES ZOSTER INFECTION}

Herpes zoster or shingles results from reactivation of the varicella zoster virus previously dormant in cranial nerves in $30 \%$ of cases. There is a predilection for the opthalmic nerve and its incidence increase with age and immunosupression $^{17,18}$. It presents as a painful unilateral intraoral, facial or ocular vesicular, pustular, and ulcerative lesions which are distributed along the area supplied by the different branches of the trigeminal nerve

The vesicles often confluent form on one side of the face and in the mouth up to the midline.

This can be an early complication of AIDS, where it is 5 times more common than in HIV-negative persons, and potentially lethal

Complications of varicella zoster infection include post herpetic neuralgia,

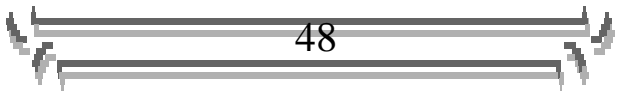


middle ear infections, motor paralysis, paraesthesia ocular inflammation, and excessive scarring leading to facial disfigurement.

Treatment is with topical acyclovir cream and gentian violet. Systemic acyclovir, valcyclovir, famciclovir, forscarnet can also be used

A case of unusual facial scarring secondary to herpes zoster infection, sharply confined to the area of the distribution of the maxillary division of the trigeminal nerve, not crossing the midline which was preceeded by itching and a vesicular rash, affecting a $32 \mathrm{yr}$ old Nigerian female was reported in UBTH. (Obuekwe et al, 2002) ${ }^{19}$. Fig 3

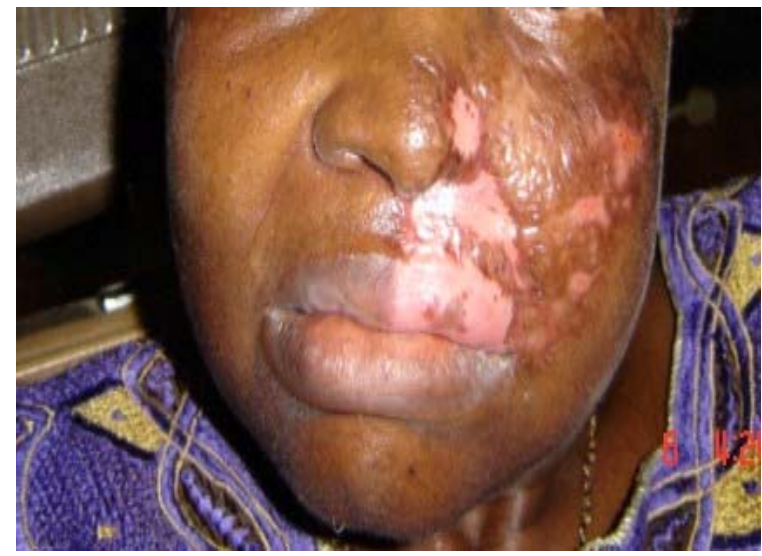

Fig. 3: Herpes Zoster

\section{BACTERIAL INFECTION}

\section{HIV-ASSOCIATED GINGIVITIS:}

HIV-associated gingivitis which is now known as Linear gingival erythema (LGE) happened to be the most frequent presentation of periodontal disease $(16.6 \%)$, it is more common than HIVassociated periodontitis $(11.7 \%)^{3}$.

Linear gingival erythema presents as a bright red line characterised by intense, asymptomatic erythema of the marginal gingival not proportional to accumulated plaque present. This may progress to HIV-associated periodontitis if not vigorously treated.

\section{HIV-ASSOCIATED PERIODONTITIS}

This include necrotising ulcerative periodontitis (NUP) characterised by extensive destruction of soft tissue and bone simultaneously leading to mobility and exfoliation of teeth, typically intensely painful and are usually generalised. It is highly prevalent amongst HIV infected children and young adults in Africa and may progress to cancrum oris as a result of malnutrition and poor oral hygiene.

HIV-associated periodontal disease also include necrotising gingivitis and accelerated periodontitis.

Necrotizing ulcerative periodontitis could be intractable and life threatening and early and aggressive treatment is necessary for its resolution ${ }^{20}$. In addition to the microbial and host factors, the role of local irritants should be considered as smoking has been identified as a strong aetiologic factor ${ }^{21}$. This condition could lead to halitosis, and is associated with a low CD4 cell count /poor prognosis.

These patients should be referred to an oral surgeon for debridement, scaling and curettage of the involved areas. This treatment is followed by administration of metronidazole (Flagyl), in a dosage of $200 \mathrm{mg}$ four times a day for five to six days, irrigation with povidone iodine and daily mouth rinsing with chlorhexidine gluconate (Peridex). Because it may potentiate peripheral neuropathy, metronidazole should not be given to patients taking didanosine (ddl; Videx) or zalcitabine (ddC; Hivid). In these patients, clindamycin (Cleocin), one 300-mg tablet three times daily, or amoxicillin, $250 \mathrm{mg}$ three times daily, is prescribed. 


\section{MYCOBACTERIUM TUBERCULOSIS}

The high prevalence of HIV coinfection with tuberculosis in developing countries including Nigeria has changed the picture of oral lesions associated with HIV infection as opposed to what is observed in the developed countries. This has led to the development of oral tuberculous lesions or ulcerations of which the common site is the posterior aspect of the dorsum of the tongue.

\section{ORAL ULCERATION}

Oral ulceration is frequently seen in HIV infection ${ }^{21}$. In a Nigerian study, the minor and major variants of recurrent aphthous ulcers accounted for $10.0 \%$. The non-recurrent type was 3.3\%. However, since recurrent aphthous ulceration is commonly encountered in most population ${ }^{22}$, it is difficult to evaluate whether its prevalence is heightened among patients with HIV infection $^{3,23}$.

\section{TUMOURS}

Kaposi's sarcoma is the most common oral malignancy associated with HIV infection and it accounts for $90 \%$ of all cancers in HIV+ patients ${ }^{24,25}$. In Nigeria, it accounts for about 3.1\%$11.6 \%$ in adults and $10 \%$ in children ${ }^{3,6,15}$. It is a tumour of vascular endothelium and presents as a flat purplish or reddish macule or nodule. The tumour is usually multifocal, with lesions affecting skin, lymph nodes and viscera. Within the mouth the palate and gingival are the most frequent sites, Fig 4. Symptoms include increasing pain, odynophagia, dysphagia and difficulty in mastication.

Occasionally, it could be of normal mucosal colour and in the early stage could be confused with other lesions.
Kaposi's sarcoma is significantly associated with death in HIV disease.

Kaposi's sarcoma in the mouth, particularly in a young male who is not receiving immunosuppressive treatment is virtually pathognomonic of $\operatorname{AIDS}^{16}$.

It is usually associated with a low CD4 lymphocyte count of < 200cells $/ \mathrm{mm}^{3}$ and frequently associated with other lesions such as candidiasis, hairy leukoplakia. It is very aggressive and has a poor prognosis. It is an indicator for profound immunosuppression. Lesion is usually asymtomatic unless when infected.

Therapy for patients with oral Kaposi's sarcoma ranges from no intervention for asymptomatic lesions to radiation, surgical removal and chemotherapy in patients with symptomatic lesions.

\section{NON-HODGKIN LYMPHOMA}

Has a reported prevalence of about $5 \%$ in developing countries. NonHodgkin's lymphoma, in contrast to Kaposi's sarcoma, occurs most commonly in intravenous drug abusers with AIDS. After Kaposi's sarcoma, this is the most common neoplasm in patients with AIDS. The lesions of nonHodgkin's lymphoma are red and exophytic, and commonly involve the alveolar ridge, the gingiva and the palate. The disease can also present as a rapidly enlarging neck mass. Most lesions are of large B-cell origin and originate extranodally. Non-Hodgkin's lymphoma can be diagnosed by tissue biopsy. The diagnosis carries a poor prognosis. Treatment varies from chemotherapy to radiotherapy or surgical excision, according to the site and extent of involvement ${ }^{26,27,28}$.

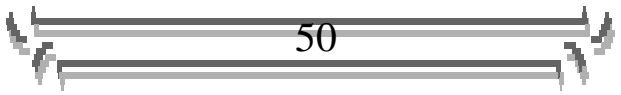




\section{LYMPHADENOPATHY}

This is characteristic of AIDS and its prodromes. Cervical lymphadenopathy seen in HIV infection is a part of the generalized lymphadenopathy and could be the most prevalent orofacial manifestation. It is probably the most common site of lymph node involvement in HIV infection. A prevalence of $5.1 \%$ in females and $4.3 \%$ in males was reported in Nigeria ${ }^{15}$.

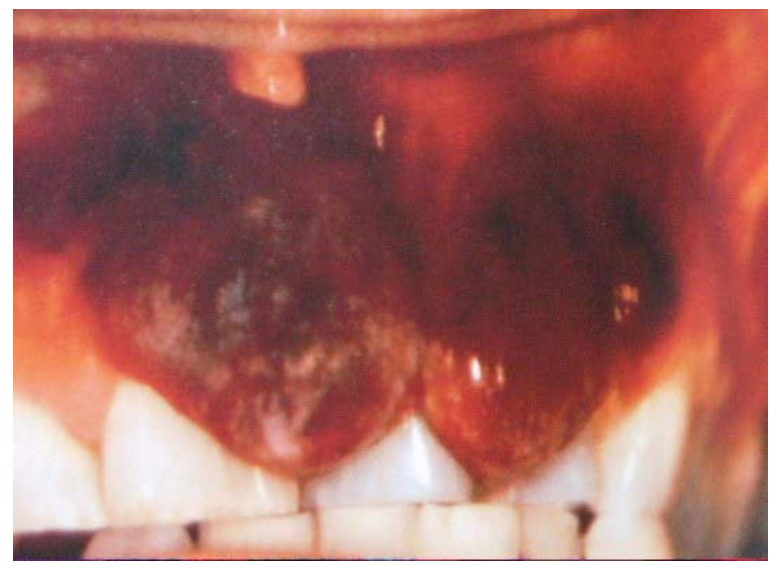

Fig. 4:Kaposi's Sarcoma ${ }^{16}$

\section{SALIVARY GLAND DISEASE}

Salivary gland disease in HIV infection can occur as xerostomia or as glandular enlargement. Xerostomia may be seen in $10-15 \%$ of patients with HIV infection. This is usually the result of HIV gland disease or secondary to medications which may produce dry mouth symptoms ${ }^{29}$. The frequency of salivary gland enlargement in Nigerian studies were reported to be $25.6 \%$ in children and $1.0-1.3 \%$ in adults ${ }^{5,15}$. The parotid gland is the most commonly affected salivary gland in HIV infection and one, or both glands could be involved, with a presentation of bilateral parotid gland swelling. The glands are soft, painless with diffuse swelling which enlarges slowly.

\section{MISCELLANEOUS ORAL COMPLICATIONS}

Autoimmune disease e.g. Thrombocytopenic purpura, it gives rise to oral purple patches which may be mistaken for Kaposi's sarcoma, and petechiae.

Oral hyperpigmentation

Neurological disease such as facial palsy and trigeminal neuralgia

Adverse drug reactions or side effects of antiviral drugs: toxic epidermal necrosis syndrome (TENS), erythema multiforme, lichenoid reactions.

Oral mucosal cytomegalovirus: this presents clinically as a large painful ulceration on any part of the oral mucosa that is non-healing and nonspecific.

\section{HIVIAIDS; CHALLENGES FACED BY THE DENTIST}

The ever increasing number of people with HIVIAIDS re-emphasizes the need for proper cross infection control in clinical practice. HIV can easily spread in the dental clinic if proper infection control practices are not followed due to the limited available facilities and lack of disposable instruments especially in the developing countries of the world. Also, the increasing number of asymptomatic HIV-positive patients that might attend for routine treatment re-emphasizes the need for adequate infection control measures in dental practice ${ }^{3}$.

Upsurge in the number of cases has put pressure on available facilities which in actual sense are not adequate and the dentist.

Stigmatization is another very important challenge in our environment. Stigma is a mark of shame and to stigmatize is to label as shameful. This is a major problem for the victims of the

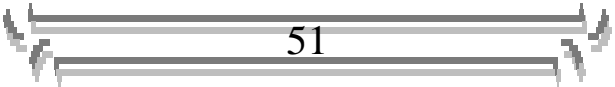


disease. The consequences of stigmatization is denial of or refusal to disclose HIV status, and this result in unmet treatment needs of these patients as some of them may shy away from seeking treatment ${ }^{5}$.

Other challenges include recurrence and persistence of orofacial infections due to immune depression and poor access to drugs for related opportunistic infections.

Removing barriers to care: The risk of transmission of HIV infection to the dentist through accidental needle-stick injuries may lead to reluctance of the dentist to treat once the HIV status of the patient is known.

The inability of attending physicians or medical examiners in the recognition of oral lesions in HIV infection in order to fit into the role of an early detector of HIV infection, and their failure to refer patient for dental care or include regular dental checkups in their routine management of HIV positive patient ${ }^{30}$. A study conducted by Cruz et al (1996) noted that medical examiners were significantly less able to identify oral lesions than dental examiners. These have management import because with the increasing number of HIV- infected individuals in the population, a thorough intraoral examination is necessary to substantiate other clinical findings that might lead to screening of such patients ${ }^{3}$.

The challenge of providing relevant and sophisticated counselling intervention to people with HIVIAIDS in order to bring healing to the emotional situation of the patient demoralized by the news of the infection and finally the late presentation of patient to the dental clinic with full blown HIV/ AIDS infection where little or nothing can be done to salvage the situation.

\section{CONCLUSION}

Orofacial lesions are common in people infected with HIV. These lesions are easily accessible and may be predictive of disease progression.

In developing countries like Nigeria were sophisticated diagnostic apparatus used to monitor the immunologic status of HIVIAIDS patients is not readily available, early recognition of the commonest and specific HIV-related oral lesions can be used for diagnosis so that prompt treatment can be provided to reduce morbidity.

\section{REFERENCES}

1. Greenspan D, Schiodt M, Greenspan JS, Pindborg JJ. AIDS and the Mouth, Diagnosis and Management of Oral Lesions. Copenhagen: Munksgaard; 1990

2. Chapple Lain LC, Hamburger J. The significance of oral health in HIV disease. Sex Transm Inf 2000; 76: 236-243.

3. Onunu AN, Obuekwe ON. HIVRelated oral disease in Benin City, Nigeria. WAJM 2002 Jan-Mar; 21(1):9-11.

4. Arotiba JT, Adebola RA, Iliyasu Z, Babashan M. Oral manifestations of HIV infection in Nigerian patients seen in Kano. Nigerian J of Surgical research 2005;7(1\&2):176-181.

5. Agbelusi GA, Wright AA. Oral lesions as indicators of HIV infection among routine dental patients in Lagos, Nigeria. Oral Dis 2005 Nov; 11(6):370-376.

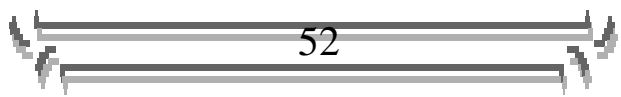


6. Taiwo OO, Pam S. Oral manifestations of HIV in Nigerian children. J Clin. Pediatr. Dent 2005; 30(1): 89-92.

7. Greenspan JS, Barr CE, Sciubba JJ, Winkler JR. Oral manifestation of HIV infection. Definition, diagnosis criteria and principles of therapy. The USA Oral Aids Collaborative Group. Oral Surg Oral Med Oral Path.1992; 73(2):142-144.

8. Taiwo OO, Okeke EN, Jalo $\mathrm{PH}$, Danfillo IS. Oral manifestation of HIVIAIDS in Plateau state indigenes, Nigeria. West Africa J Med 2006 Jan-Mar; 25(1): 32-7.

9. Tukutuku K, Muyembe-Tamfun L, Kayembe K, Odion W, Kandi K, Ntumba M. Oral manifestation of AIDS in a heterosexual population in a Zaire hospital. J oral pathol Med. 1990; 19: 232-234.

10. Greenspan JS, Sentinel and signposts. The epidemiology Petit JC, Ripamonti U, Helle J. Progressive changes of kaposi sarcoma of the gingiva and palate. Case report in an AIDS patient. J Periodontal. 1986; 57: 159-163.

11. Petit JC, Ripamonti U, Helle J. Progressive changes of Kaposi's sarcoma of the gingiva and palate. Case report in an AIDS patient. $J$ periodontal. 1986; 57: 159-163.

12. Lynch DP. Oral manifestations of HIV disease: an update. Semin Cutan Med Surg. 1997, 16: 257-264.

13. Greenspan D, Greenspan JS. Management of the oral lesions of HIV infections. JADA 1991; 1222: 26-32.
14. Taiwo OO, Danfillo IS, Okeke EN. Oral manifestations of HIVIAIDS in Jos, Nigeria. Africa J of Oral Health Sciences 2003 Nov/Dec; 4(3).

15. Obuekwe ON, Onunu AN. Gender and Oral manifestations of HIV infection among adult Nigerians. Africa J of Reproductive Health 2006 Aug; 10(2):81-89.

16. Cawson RA, Odell EW, Porter S. Immunodeficiencies and HIV disease. Textbook of Oral pathology and oral medicine 2002; pg. 308316.

17. Carreau JP, Gola R, Cheynet F, Guyot L. Zona of the cranial nerves. Current aspects. Rev Stomatol Chir Maxillofac. 1998; 99: 155-164.

18. Morgan R, King D. Shingles: a review of diagnosis and management. Hosp. Med. 1998; 59: 770-776.

19. Obuekwe ON, Ojo MA, Madukwe IU. Unusual facial scarring - an orofacial manifestation of AIDS. Benin $\mathrm{J}$ of Postgraduate Medicine. 2002 Dec; 6(1): 105-107.

20. Williams CA, Winkler JR, Grassi M, Murray PA. HIV-associated periodontitis complicated by necrotizing stomatitis. Orag Surg. Oral Med Pathol, 1990; 69(3): 351-5.

21. Palmer GD, Robinson PG, Challacombe SJ, Bimbaum W. Aetiologic factors for oral manifestations ofHIV. Oral Dis. 1996; 2(3):193-7.

22. Lamey PJ, Lewis MAO. Oral medicine in practice: Oral ulceration. Br Dent J. 1989; 167:127-131.

23. Pindborg JJ. Classification of oral lesions associated with HIV infection.

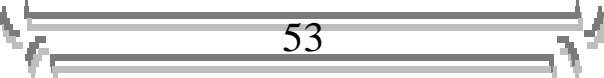


Oral Surg. Oral Med Oral Pathol. 1989; 67:292-5.

24. Convissar RA. Laser palliation of oral manifestations of human immunodeficiency virus infection. JADA 2002; 133: 591-598.

25. Flaitz C, Nichols C, Hicks M. An overview of the oral manifestations of AIDS-related Kaposi's sarcoma. Compend Contin Educ Dent 1995; 15: 136-148.

26. Dichtel WJ Jr. Oral manifestations of human immunodeficiency virus infection. Otolaryngol Clin North Am 1992; 25: 1211-26.
27. Green TL, Eversole LR. Oral lymphomas in HIV-infected patients: association with Epstein-Barr virus DNA. Oral Surg Oral Med Oral Pathol 1989; 67:437-42.

28. Kaugars GE, Burns JC. NonHodgkin's lymphoma of the oral cavity associated with AIDS. Oral Surg Oral Med Oral Pathol 1989; 67: 433-6.

29. Naidoo S, Chikte U. HIVIAIDS- the evolving pandemic and its impact on oral health in sub-Saharan African. S Afr Dent J 1999; 54:616-630.

30. Sofola OO, Uti OG, Emeka O. Access to oral health care for HIV patients in Nigeria: Role of attending physicians. African $\mathrm{J}$ of Oral Health 2004 Sep; 1(1): 37-41.

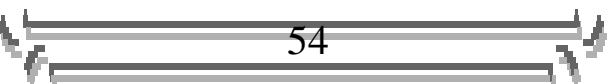

